\title{
Usage of Ionic liquids as additives in ion exchange chromatography for the analysis of inorganic anions
}

\author{
Huawei Dia, Chengyin Wanga, Xiashi Zhu ${ }^{\mathrm{a}, *}$, \\ aYangzhou University, No. 88 South University Road, Yangzhou and 225002, China
}

*Corresponding Author: xszhu@yzu.edu.cn

\begin{abstract}
A research of the performance of five imidazolium-based ionic liquids (ILs) (the bromides, tetrafluoroborates and hexafluorophosphates of 1-butyl, 1-hexyl and 1-octyl-3methylimidazolium) as additives in ion exchange chromatographic (IEC) behavior of inorganic anion $\left(\mathrm{NO}_{3}{ }^{-}\right)$ was studied. The results showed that the IL 1-butyl-3methyl-imidazolium hexafluorophosphate (BMIMPF 6$)$ offered the most interesting feature in separation of inorganic anions, such as lower retention time and great peak height. In order to separate anions effectively, the best condition was selected that is to add $0.30 \mathrm{mM} \mathrm{BMIMPF}_{6}$ in IEC mobile phase for desperation of nitrate with the flow rate of 0.7 $\mathrm{mL} \cdot \mathrm{min}^{-1}$ at room temperature. In the range of 1.0 60 $\mu \mathrm{g} \cdot \mathrm{mL}^{-1}$, linear equations of nitrate was made. The limit of detection of nitrate was $4.4 \mu \mathrm{g} \cdot \mathrm{L}^{-1}$. In this work, nitrate in water samples were detected successfully.
\end{abstract}

Keywords: ionic liquids, ion exchange chromatography, mobile phase.

\section{Introduction}

Ion exchange chromatography (IEC), established by $\mathrm{H} \cdot$ Small in $1975^{(1)}$, has become a popular chromatographic technique for the analysis of organic and inorganic ions in water quality control procedures. Its highly selective separation mostly depends on the mobile phase composition, when the stationary phase was chosen ${ }^{(2)}$. Therefore, the mobile phase of IEC received much attention.
The common mobile phases in IEC are sodium hydroxide ${ }^{(3)}$, potassium hydroxide ${ }^{(4)}$, sodium carbonate ${ }^{(5)}$ and sodium bicarbonate ${ }^{(6)}$. Carbonate was an attractive mobile phase for IEC mobile phases which was often used because of its good exchange capacity, non-pollution and convenience for separation of the common anions (7). However, it also has some shortcomings. Carbonate as IEC mobile phase could separate anions with moderate retention capacity (such as $\mathrm{Cl}^{-}, \mathrm{NO}_{2}^{-}, \mathrm{Br}^{-}, \mathrm{NO}_{3}^{-}$) in a short time ${ }^{(8)}$, but anions with low retention capacity $\left(\mathrm{F}^{-}, \mathrm{HCOO}^{-}, \mathrm{CH}_{3} \mathrm{COO}^{-}\right.$, $\left.\mathrm{AsO}_{2}^{-}, \mathrm{CN}^{-}, \mathrm{S}_{2}^{-}\right)$and anions with high retention capacity ( $\mathrm{I}^{-}$, $\mathrm{SCN}^{-}, \mathrm{S}_{2} \mathrm{O}_{3}{ }^{2-}$ ) could not be separated very well. If these anions are to separate successfully, the utmost effort must be made by researchers to modify the mobile phase, such as increasing the concentration of carbonate, or adding additives in it. It has been reported in the paper ${ }^{(9)}$ that high concentration of carbonate can be chosen to exchange highly retained ions in a short time. However, it can also lead to high background conductivity and low resolution of similar components ${ }^{(10)}$. Accordingly, additives, such as methanol ${ }^{(11)}$, acetone $^{(12)}$, acetonitrile ${ }^{(13)}$, acrylonitrile ${ }^{(14)}$, zwitterions ${ }^{(15,16)}$ were frequently added in IEC mobile phase, which can improve the selectivity and sensitivity of highly retained ions.

In general, ILs can be used as salts or solvents because of their many special nature. As solvents, they have a nonmolecular nature with special features: low vapor pressure and high thermal stability, low volatility and flammability ${ }^{(17,18)}$. ILs also have been considered as alternative additives commonly used in chromatographic analysis. For example, in gas chromatography (GC), Butyl-3-methylimidazole and 1-butyl-3-methylimidazolium hexafluorophosphate were 
coated in the surface of GC stationary phase by Armstrong to study the interaction between ILs and sample molecules (19). In high performance liquid chromatography (HPLC), bromobutyl imidazole was covered in the surface of the HPLC silane stationary phase to detect 28 kinds of aromatic compounds in Sun's laboratory ${ }^{(20)}$. In reversed-phase liquid chromatography (RPLC), ILs were used as alternative additives (i.e. salts) to enhance the peak performance in the analysis of basic compounds, using conventional stationary phases ${ }^{(21)}$. In capillary chromatography, ILs have been used as modifiers of quartz capillary surface to analyze drug molecules ${ }^{(22)}$. In these reported papers ${ }^{(19-22)}$, ILs were added in the mobile phase and coated in the surface of the stationary phase to enhance the performance of analytes to improve the selectivity of tested analytes. Rare published papers reported that ionic liquids (ILs) had been added in IEC mobile phase.

In this work, the research were done and increasing concentrations of different kinds of ILs were put in IEC mobile phase to discover the behavior of the tested anions and to find the suitable IL under this system. The interaction mechanism of ILs with stationary phase and analytes was discussed, and the validation parameters of this method were detected too. Finally, actual environment samples were tested successfully.

\section{Experimental}

\subsection{Reagents and apparatus}

The mobile phases contained sodium carbonate and sodium bicarbonate (Guanglinqihua, Yangzhou, China) and one of the following ILs: 1-butyl-3-methylimidazolium hexafluorophosphate $\left(\mathrm{BMIMPF}_{6}\right)$, 1-hexyl-3- methylimidazolium hexafluorophosphate $\left(\mathrm{HMIMPF}_{6}\right)$, 1-octyl-3methylimidazolium hexafluorophosphate $\left(\mathrm{OMIMPF}_{6}\right), 1-$ butyl-3-methylimidazolium tetrafluoroborate $\left(\mathrm{BMIMBF}_{4}\right)$, 1-butyl-3-methylimidazolium bromide (BMIMBr). All ILs were synthesized in the laboratory. $0.05 \mathrm{~mol} \mathrm{n}$-methylimidazole and $0.05 \mathrm{~mol} 1$-bromobutane were put into a three-necked flask and refluxed for $4 \mathrm{~h}$ with stirring at 250 $\mathrm{r} \cdot \mathrm{min}^{-1}$, then washed by toluene three times and dried in the Vacuum drying oven for $6 \mathrm{~h}$ in $70{ }^{\circ} \mathrm{C}$. The other ILs were made by the same methods ${ }^{(23)}$.

The sample solutions and mobile phases were passed through $0.45 \mu \mathrm{m}$ membranes or $0.22 \mu \mathrm{m}$ MCE (SHIMADZU-GL). Ultrapure water (Millipore, German) was used throughout. Standard solutions were prepared (EST
Technology co, Shenzhen, China). A mobile phase containing a fixed concentration of sodium carbonate (3.2 $\mathrm{mM})$ and sodium bicarbonate $(1.0 \mathrm{mM})$ was selected as a reference. The ILs BMIMPF $6, \mathrm{HMIMPF}_{6}, \mathrm{OMIMPF}_{6}$, $\mathrm{BMIMBF}_{4}, \mathrm{BMIMBr}$ were then added.

\subsection{Instrumental}

MIC 940 ion chromatography from Metrohm (Shanghai, China) was used throughout. The instrument was equipped with an IEC Cube module, which included an injection valve, a degas cartridge, column heater, guard column (Metrosep A supp 4/5 Guard 4.0), separator column (Metrosep A Supp 5150/4.0), a suppressor (ACES 300) and a carbonate removal device (CRD 200). A conductivity detector (CD) was used for detection. The samples were injected via an 850 Autosampler (Metrohm, Shanghai, China). The system was controlled by MagIC 3.0 software.

Table 1. Instrumental parameters for anion determination by

\begin{tabular}{|c|c|}
\hline \multicolumn{2}{|c}{ MagIC. } \\
\hline Column (dimensions) & $\begin{array}{c}\text { Metrosep A Supp 5- } \\
150 / 4.0\end{array}$ \\
\hline Guard (dimensions) & Metrosep A supp 4/5 \\
Guard 4.0
\end{tabular}

Table 2. Eluent for anion determination by MagIC.

\begin{tabular}{|c|c|}
\hline Eluent 1 & $3.2 \mathrm{mM} \mathrm{Na}_{2} \mathrm{CO}_{3}+1.0 \mathrm{mM} \mathrm{NaHCO}_{3}$ \\
\hline Eluent 2 & $3.2 \mathrm{mM} \mathrm{Na}_{2} \mathrm{CO}_{3}+1.0 \mathrm{mM} \mathrm{NaHCO}_{3}+$ \\
& $0.1,0.2,0.3,0.4,0.6,0.8,1 \mathrm{mM} \mathrm{ILs}$ \\
\hline
\end{tabular}

Anion separation was carried out at $25^{\circ} \mathrm{C}$. Applying a flow rate of $0.7 \mu \mathrm{L} \cdot \mathrm{min}^{-1}$, the separation of anions was achieved in $20 \mathrm{~min}$, injecting $20 \mu \mathrm{L}$ of sample. MagIC operating conditions used for anion determination, along with chromatographic parameters.

\section{Results and Discussion}

\subsection{Modification of Mobile Phase by ILs}

(b) $\mathrm{Pe}$

(c) 
In previous studies, the improvement of chromatographic separation of analysis using ILs ${ }^{(19-22)}$, but rare conclusions about ILs in IEC mobile phase were made. With adding varied concentrations of five ILs composed of different cations and anions in IEC mobile phase, the retention time and peak height of nitrate can be improved obviously. In order to search the optimum experimental condition, the flow rate of mobile phase and temperature of stationary phase (column) were studied later.

\subsubsection{Effect of ILs on the Retention Time of anion}

In the experiment, the effects of the anions and cations of different ILs on the retention time of nitrate in IEC mobile phase were investigated respectively. The cations of ILs mainly contain $\mathrm{C}_{n} \mathrm{MIM}^{+}(\mathrm{n}=4,6,8)$ and the anions of ILs consist of $\mathrm{PF}_{6}^{-}, \mathrm{BF}_{4}^{-}$and $\mathrm{Br}^{-}$. The concentration range for these ILs was added between 0.1 and $1.0 \mathrm{mM}$ (the background conductivity will be unstable when the concentrations of ILs $\geq 1.0 \mathrm{mM}$ ). (Figure 1. a)

The changes in the retention time of nitrate at varied concentrations of different kinds of ILs cations were depicted in Fig.1a. The retention time of nitrate decreased systematically with an increasing concentration of ILs in IEC mobile phase. Also the retention time would be reduced when the carbon chain of ILs cations decreased mildly (the lowest retention time of nitrate in the presence of $\mathrm{C}_{4} \mathrm{MIM}^{+}$). Interestingly, the difference of the influence by these cations on retention time of nitrate was found to be slightly.

Compared with carbonate in IEC mobile phase, the retention time would be reduced as the anions of ILs have stronger binding capacity with stationary phase, and the retention time would be decreased most with respect to $\mathrm{HMIM}^{+}$and $\mathrm{OMIM}^{+}$in the carbonate mobile phase in the presence of $\mathrm{BMIM}^{+}$. The reason was that the shorter the carbon chain of ILs cations is, the stronger the hydrophily it has ${ }^{(24)}$. $\mathrm{BMIM}^{+}\left(\mathrm{C}_{4} \mathrm{MIM}^{+}\right)$has the shortest carbon chain among them, therefore, it has lowest viscosity ${ }^{(17)}$, which could not affect the flow rate of mobile phase. However, $\mathrm{OMIM}^{+}\left(\mathrm{C}_{8} \mathrm{MIM}^{+}\right)$in mobile phase could reduce the flow rate of it, and the retention time of nitrate would not decreased.

With the increasing concentration of ILs anions, the retention time of nitrate would be reduced, and the retention time decreased most in the presence of $\mathrm{PF}_{6}{ }^{-}$, compared with $\mathrm{BF}_{4}^{-}$and $\mathrm{Br}^{-}$(Fig. 1a). This is becuase of the affinity of $\mathrm{PF}_{6}^{-}$ with the stationary phase which made a great effort in increasing flow rate of nitrate in stationary phase. The radius of $\mathrm{PF}_{6}^{-}$was much bigger than $\mathrm{BF}_{4}^{-}, \mathrm{Br}^{-}$and $\mathrm{HCO}_{3}^{-}$(Fig. 1a.), so it could combine with stationary phase firmly, which lead to low retention time of nitrate.

Both anions and cations of ILs have an effect on the reduction of retention time, but the influence of anions was stronger than that of cations. In this work, $\mathrm{BMIMPF}_{6}$ was chosen as the best additive added in IEC mobile phase finally.

\subsubsection{Effect of IL on the peak performance of anion}

Varied concentrations of BMIMPF6 in IEC mobile phase, as the optimal additive, was responsible for selecting the information of analytical peak height (Fig. 1b.). With the increase of IL concentration, the peak height of nitrate increased first, and decreased again when the concentration was greater than $0.3 \mathrm{mM}$.

When the concentration of IL was small $(\leq 0.3 \mathrm{mM})$, IL could improve the exchange rate of nitrate in the system and reduce the peak width of nitrate ${ }^{(17)}$, thereby the peak height would increase (a). However, when the concentration of IL was too large ( $\geq 0.3 \mathrm{mM}$ ), higher background conductivity and unstable background conductivity would appear (b), which could cause low peak height. As the result, the optimal concentration of BMIMPF6 was $0.3 \mathrm{mM}$.

\subsubsection{Flow rate}

As an important part of IEC system, the flow rate of mobile phase was configured as critical mode which would affect the retention time of analytes and change the pressure of stationary phase (column). The retention time of nitrate would be reduced and the pressure of column increased when the flow rate of mobile phase increased from $0.4 \mathrm{~mL} \cdot \mathrm{min}^{-1}$ to $0.8 \mathrm{~mL} \cdot \mathrm{min}^{-1}$. If the flow rate was larger than $0.7 \mathrm{~mL} \cdot \mathrm{min}^{-}$ ${ }^{1}$, the pressure would be larger than $2.5 \mathrm{MPa}$, which would cause damage to the column after using repeatedly. In this work, $0.7 \mathrm{~mL} \cdot \mathrm{min}^{-1}$ of flow rate was chosen.

\subsubsection{Temperature}

In the whole IEC system, the temperature of column played an important role, which could changed the retention time of nitrate. In this work, different temperature and same other conditions (stationary phase, mobile phase and flow rate) were selected. When the temperature of column increased from $20^{\circ} \mathrm{C}$ to $40^{\circ} \mathrm{C}$, the pressure of the column and the retention time of nitrate were almost unchanged, which indicated that the temperature of column did not influence 
the behavior of analytes in this method. In convenience, room temperature was chosen.

\subsubsection{The influence of additives on the analytical properties}

The influence of different mobile phases on the properties of seven anions were shown in Fig. 1.c. IEC mobile phases with and without additives were employed for separating the analytes.

Table 3. Linear range and related parameters.

\begin{tabular}{|c|c|c|c|c|}
\hline & $\begin{array}{c}\text { Linear range } \\
(\mathrm{mg} / \mathrm{L})\end{array}$ & Linear equations & $\begin{array}{c}\text { Correlation } \\
\text { coefficient }\end{array}$ & $\begin{array}{c}\mathrm{LOD} \\
(\mu \mathrm{g} / \mathrm{L})\end{array}$ \\
\hline Nitrate & $1.0 \sim 60$ & $\mathrm{H}=0.1106 \mathrm{c}-0.02948$ & 0.9995 & 4.40 \\
\hline
\end{tabular}

$\mathrm{F}^{-}, \mathrm{Cl}^{-}, \mathrm{SO}_{4}{ }^{2-}, \mathrm{I}^{-}, \mathrm{NO}_{2}{ }^{-}, \mathrm{Br}^{-}, \mathrm{NO}_{3}{ }^{-}$could not be separated within 20 min when the mobile phase was not modified by additive (Fig. 1.c.A). Since IL was added in IEC mobile phase, the retention time of seven anions was shorten and the peak shape was improved (Fig. 1.c.B). The selectivity and resolution of analytes were improved as well. For example, there was a significant decrease in retention time of iodide as compared to the other six anions and the separation between iodide and sulfate was better (Fig. 1.c.B). Therefore, using $0.3 \mathrm{mM}^{\mathrm{BMIMPF}} 6 \mathrm{~B}_{6}$ in IEC mobile phase can greatly improve the behavior of anions.

\subsection{Method validations}

A group of various concentrations standard solutions were tested to detect the precision and linear range of this method under the optimized conditions. The limits of detection (LOD) in this experiment and in other experiments were compared.

\subsubsection{Method Precision}

Repeatability of the chromatographic system was tested under the chromatographic conditions previously selected by means of 9 replicate injections of a solution with $20 \mu \mathrm{g} \cdot \mathrm{mL}$ ${ }^{1}$ nitrate and bromide and finding out the peak height by the proposed method. From these data, \%RSD of peak height were calculated (nitrate: $0.10 \%$, bromide: $0.13 \%$ ).

\subsubsection{Analytical performance}

The standard solution of varied concentrations was injected three times. Linear equation were obtained based on the results of chromatographic analysis of bromide and nitrate standard solutions. The equations were calculated according to peak height $\left(\mu \mathrm{S} \cdot \mathrm{cm}^{-1}\right)$ and concentrations $\left(\mu \mathrm{g} \cdot \mathrm{mL}^{-1}\right)$ of analytes. LOD were tested by the concentration of nitrate and bromide giving a signal to noise ratio of $3: 1$ respectively.

\subsubsection{Comparison with other methods}

For the purpose of ensuring this method application, the comparison of linear range and LOD between this method and others in reported studies ${ }^{(21-25)}$ were adopted. The results

Table 5. Linear range and related parameters.

\begin{tabular}{|c|c|c|c|}
\hline $\begin{array}{c}\text { Foreign } \\
\text { ions }\end{array}$ & $\begin{array}{c}\text { Foreign/ } \mathrm{NO}_{3}{ }^{-} \\
(\mathrm{w} / \mathrm{w})\end{array}$ & Foreign ions & $\begin{array}{c}\text { Foreign/ } / \mathrm{NO}_{3}{ }^{-} \\
(\mathrm{w} / \mathrm{w})\end{array}$ \\
\hline $\mathrm{F}^{-}$ & 180 & $\mathrm{NO}_{2}{ }^{-}$ & 60 \\
\hline $\mathrm{Cl}^{-}$ & 180 & $\mathrm{SO}_{4}{ }^{2-}$ & 100 \\
\hline $\mathrm{Br}^{-}$ & 100 & $\mathrm{I}^{-}$ & 100 \\
\hline
\end{tabular}

Table 6. Determination of water samples and recovery

\begin{tabular}{|c|c|c|c|c|}
\hline $\begin{array}{c}\text { Water } \\
\text { sample/NO }\end{array}{ }^{-}$ & $\begin{array}{c}\text { Add } \\
(\mathrm{mg} / \mathrm{L})\end{array}$ & $\begin{array}{c}\text { Test[a] } \\
(\mathrm{mg} / \mathrm{L})\end{array}$ & Recovery/\% & RSD/\% \\
\hline \multirow{2}{*}{$\begin{array}{c}\text { Slender } \\
\text { west lake } \\
\text { water }\end{array}$} & 0 & 0.32 & & \\
\cline { 2 - 5 } & 1 & 1.51 & 118.4 & 1.40 \\
\cline { 2 - 5 } & 2 & 2.63 & 115.3 & 0.37 \\
\cline { 2 - 5 } & 3 & 3.76 & 114.5 & 0.80 \\
\cline { 2 - 5 } & 4 & 4.76 & 110.8 & 1.95 \\
\hline \multirow{2}{*}{ Tap water } & 0 & 0.29 & & \\
\hline \multirow{3}{*}{} & 1 & 1.46 & 117.2 & 1.07 \\
\hline & 2 & 2.57 & 114.1 & 2.49 \\
\hline & 4 & 3.64 & 111.6 & 0.60 \\
\hline
\end{tabular}

[a]: average value of three determination

shown in Table 4 indicated that ILs in mobile phases modified the behavior of inorganic anions in stationary phase effectively. Therefore, ILs in mobile phase had better application for analyzing anions compared with others. (Table 4)

\subsection{Real sample analysis}

\subsubsection{Interference experiment}

In order to find whether other anions in real samples could affect analysis of nitrate, the effects of common anions on the determination of nitrate were studied. 
As can be seen from Table 5, if the concentration of most common anions in the system was found between 60 to 180 times of nitrate, it could lead to the interference of nitrate analysis. Therefore in the actual water sample, the interference of common anions to the determination of $\mathrm{NO}_{3}$ was almost nonexistent while this method was applied.

\subsubsection{Sample analysis}

The developed method was applied to analyze two anions in real water samples. The concentrations of analytes were calculated and the results can be seen in Table 6 . The recovery values were close to $100.0 \%$, with a range of 110.8 to $118.4 \%$, and most of the RSD were under $2.0 \%$. The concentration of nitrate was $1.44 \mu \mathrm{g} \cdot \mathrm{mL}^{-1}$ and $1.31 \mu \mathrm{g} \cdot \mathrm{mL}^{-1}$ in water sample of slender west lake and tap water, respectively. Both of the results met health standards for drinking water issued by the Ministry of Health of the People's Republic of China (GB 5749-2006).

\section{Conclusions}

In this work, the method was presented to complete the comparison of analytical behavior of anions when different ILs adding in the mobile phase, different flow rate of mobile phase and temperature of column. Among which, the optimal condition was that $\mathrm{BMIMPF}_{6}$ acted as the best additive in IEC mobile phase with $0.7 \mathrm{~mL} \cdot \mathrm{min}^{-1}$ at $25^{\circ} \mathrm{C}$. The retention time of nitrate and bromide were improved and changed well. In real sample analysis, IEC provided a rapid assay of inorganic ions in water samples successfully. and a project funded by the Priority Academic Program Development of Jiangsu Higher Education Institutions.

\section{References}

(1) H. Small, T.S. Stevens, and W.C. Bauman : "Novel ionexchange chromatographic method using conductometric detection", Anal. Chem. 47, 11, pp. 1801-1809, 1975

(2) C.A Lucy, and P Hatsis: "Effect of temperature on retention and selectivity in ion chromatography of anions", Journal of Chromatography A, 920, 1-2, pp. 311,2001

(3) A.J. Vella, C. Chircop, T. Micallef, and C. Pace: "Perchlorate in dust fall and indoor dust in Malta: an effect of fireworks", Sci. Total Environ, 521, 1, pp. 4651,2015

(4) Anna S. Uzhel, Alexandra V. Zatirakha, and Konstantin N. Smirnov: "Anion exchangers with negatively charged functionalities in hyperbranched ion-exchange layers for ion chromatography", Journal of Chromatography A, 1482, 27, pp. 57-64, 2017

(5) J.C. Gandhi: "Simultaneous determination of anions and oxyhalides , US EPA 300.1, by sequential suppressed ion chromatography in a single injection analysis", LCGC Europe, 20, 3, pp. 12-12, 2007

(6) Metrohm, Oxyhalides besides Standard Anions in

Table 4. Comparison of different methods.

\begin{tabular}{|c|c|c|c|c|}
\hline Anion & Mobile phase & $\begin{array}{l}\text { Linear range } \\
(\mathrm{mg} / \mathrm{L})\end{array}$ & $\mathrm{LOD}(\mu \mathrm{g} / \mathrm{L})$ & References \\
\hline \multirow[t]{4}{*}{$\mathrm{NO}_{3}^{-}$} & $30.0 \mathrm{mM} \mathrm{NaOH}$ & $0.00 \sim 200.00$ & 16 & (25) \\
\hline & $\begin{array}{c}4.8 \mathrm{mM} \mathrm{Na} \mathrm{CO}_{3}+0.6 \mathrm{mM} \\
\mathrm{NaHCO}_{3}\end{array}$ & $0.10 \sim 120.00$ & 6 & (26) \\
\hline & $\begin{array}{c}8.0 \mathrm{mM} \mathrm{Na} \mathrm{CO}_{3}+1.0 \mathrm{mM} \\
\mathrm{NaHCO}_{3}\end{array}$ & 1 & 100 & (27) \\
\hline & $\begin{array}{c}3.2 \mathrm{mM} \mathrm{Na}_{2} \mathrm{CO}_{3}+1.0 \mathrm{mM} \\
\mathrm{NaHCO}_{3}+0.3 \mathrm{mM} \mathrm{BMIMPF} 6\end{array}$ & $1.00 \sim 60.00$ & 4.4 & This method \\
\hline
\end{tabular}

\section{Acknowledgment}

The authors acknowledge the financial support from the National Natural Science Foundation of China (21375117)
Swimming Pool Water, 2015.

(7) B. Fu, X.J. Wang, and Z.Y. Ye: "Deteration of chloride and sulfate content in chromium trioxide by ion chromatography”, Huaxue Shiji, 38, 7, pp.149-152, 177,2016 
(8) G.B. Shen, Y.F. Lu, F.F. Chen, and F.F. Zhang: "Fabrication and evaluation of an electrodialytic carbonate eluent generator for ion chromatography", Talanta, 159, 1, pp.143-147, 2016

(9) J. Li, Y. Wang, and L.N. Liang: "Simultaneous analysis of iodide and thiocyanate in power milk using ion chromatography", Fenxi Shiyanshi, 29, 5, pp.17-20 , 2010

(10) P. Song, Q.E. Wang, and M.Y. Ding: "Determination of anions in intermediates and products of the production of m-phthalic acid by ion chromatography", PTCA, PART B:CHEM.ANAL, 42, 2, pp. 1016-1018 , 2006

(11) J.B. Long, J.S. Zhou, and H.Y. Zhang: "Determination of acetic acid, tartaric acid, sorbic acid and benzoic acid in beverages added organic modifier by ion chromatography", Chinese Journal of Health Laboratory Technology, 20, 3, pp. 1025-1227, 2010

(12) J. Yao, J.M. Zhu, and M. Chen: "Determination of thiocyanate in milk by on-line dialysis-ion chromatography", Chinese Journal of Health Laboratory Technology, 21, 4, pp. 824-826, 2011

(13) C. Kukusamude, R. Burakham, and O. Chailapaku: "High performance liquid chromatography for the simultaneous analysis of penicillin residues in beef and milk using ion-paired extraction and binary wateracetonitrile mixture", Talanta, 92, 15, pp. 38-44, 2012

(14) Stepnowski P, Mrozik W, and Nichthauser J: “Analysis of environmental fate and quantitative methods for determination of ionic liquids". Journal of Magnetic Resonance Imaging, 24, 4, pp. 796-800, 2007

(15) Y.J. Chen: "Ion Chromatography using Zwitterion as eluents”, Zhejiang University, Zhejiang, 2006.

(16) C.Q. Huang, L.L. Wang, and Y. Zhu: "Determination of chloride and phosphate in heteropoly acid by mobile phase ion chromatography", Chinese journal of analytical chemistry, 34, 11, pp. 1641-1643, 2006

(17) M.T. Ubeda-Torres, C. Ortiz-Bolsico, and M.C. GarcíaAlvarez-Coque: "Gaining insight in the behaviour of imidazolium-based ionic liquids as additives in reversed-phase liquid chromatography for the analysis of basic compounds", Journal of Chromatography A, 1380, 6, pp. 96-103, 2015
(18) A. Berthod, M.J. Ruiz-Angel, and S. Carda-Broch: "Ionic liquids in separation techniques", Journal of Chromatoghy A, 1184, 1, pp. 6-18, 2008

(19) D.W. Armstrong, L.F. He, and Y.S. Liu: "Examination of ionic liquids and their interaction with molecules, when used as stationary phases in gas chromatography", Anal Chem, 71, 17, pp. 3873, 1999

(20) Y. Sun, B. Cabovska, and C.E Evans: "Retention characteristics of a new butylimidazolium-based stationary phase", Anal Bioanal Chem, 382, 3, pp. 728, 2005

(21) W.Z. Zhang, L.J. He, and Y.L. Gu: "Effect of ionic liquids as mobile phase additives on retention of catecholamines in reversed-phase high-performance liquid chromatography”, Anal Lett, 36, 4, pp. 827, 2003

(22) W.D. Qin, and S.F.Y. Li: “An ionic liquid coating for determination of sildenafil and UK-103, 320 in human serum by capillary zone electrophoresis-ion trap mass spectrometry". Electrophoresis. 23, 24, pp. 4110, 2002

(23)F. Dong, C. Jian, and G. Kai: "A green and novel procedure for the preparation of ionic liquid", Journal of Fluorine Chemistry, 129, 21, pp. 108-111, 2008

(24)Q.Q. Baltazar, J. Chandawlla, and K. Sawyer: "Interfacial and micellar properties of imidazoliumbased monocationic and dicationic ionic liquids", Colloids \& Surfaces A Physicochemical \& Engineering Aspects, 302, 1, pp. 150-156, 2007

(25) F. Zhang: "Research and application on groundwater by ion chromatography method in the detection of fluoride, chloride, sulfate, nitrate, bromine and iodine", Jiling University, Jiling, 2014.

(26) Y. Li, X.S. Liu, and F. Zhou: "Rapid determination of four anions in drinking water by ion chromatography", PTCA, PART B:CHEM.ANAL, 42, 10, pp. 836-838, 2006

(27) Y.J. Wang, and L. Ye: "Seven kinds of anion determination in water with ion chromatography", Pollution Control Technology, 18, 3, pp. 51-52, 2005 